\title{
Control of liverwort (Marchantia polymorpha L.) growth in nursery plants with mulches of Sphagnum moss and blackcurrant stem pieces
}

\author{
Liisa E. Särkkä and Risto Tahvonen \\ Natural Resources Institute Finland (Luke), Itäinen Pitkäkatu 4A, FI- 20520 Turku, Finland \\ e-mail: liisa.sarkka@luke.fi
}

\begin{abstract}
Liverwort (Marchantia polymorpha L.) is a problematic weed on container surfaces in nurseries, because it hampers water and nutrient access to growing plants. No chemical herbicide against it is available in the EU. Mulches are the most common non-chemical weed control method. Mulches of Sphagnum moss and 1-cm blackcurrant stem pieces were used. Mulches' effect on liverwort control continued for two years on highbush blueberry and blackcurrant, and one year on rhododendron. The blackcurrant stem pieces trial continued for one year. Blueberry and rhododendron demand acidic growing media, creating an acute need for liverwort control. Sieved moss was used in two different layers on top of a pot. The prevention rate of liverwort growth in blueberry in July-August was 95-99\%, and in October 78-90\%, depending on weather conditions; in rhododendron and blackcurrant, it was 90-95\%.The control effect was diminished in more decomposed moss. No significant difference between thickness and coarseness of moss mulch layers was observed. Blackcurrant stem pieces controlled liverwort growth by almost $100 \%$.
\end{abstract}

Key words: blueberry, container plant, rhododendron, Sphagnum fuscum

\section{Introduction}

Liverwort (Marchantia polymorpha L.) is one of the most harmful weeds in commercial plant nurseries worldwide, because it spreads efficiently on the surface of plant containers and is a strong competitor for water and nutrients during the propagation of container-grown nursery crops (Fausey 2003). Automatic sprinkler irrigation systems in nurseries especially encourage liverwort growth, because regular availability of water generates a beneficial environment for the growth and spread of liverwort (Hammett 1976). In addition, water runs along the leatherlike surface of liverwort out of the container and may cause a lack of water for the plants. The growth of the plants slows down, extending the growing time for a saleable product. Liverwort is also an aesthetic disadvantage when selling plants. No chemical pesticide is authorised in the EU to control liverwort on the surface of pot plants. Liverwort thrives in very similar conditions to the plants to be propagated. In the early stages of growth, a high relative humidity and/or moisture substrate promote its growth. However, liverwort shows some resistance to drought (Poteri 2002), although the air pores on the dorsal surface is believed not to close like stomata when there is a shortage of water (Shimamura 2016). The optimum day length for liverwort growth is 13-15 hours (Newby et al. 2006). Low light intensity, low UV irradiation (Newby et al. 2006), and high nutrition conditions (Voth and Hamner 1941) are also required. The most favourable temperature range for sexual reproduction is $10-15^{\circ} \mathrm{C}$, and for vegetative growth, $18-22{ }^{\circ} \mathrm{C}$ (Newby et al. 2006).

Liverwort has a leaf-like thalli that adheres firmly to the surface of the container with the help of rhizoids (Newby et al. 2007). Removing it mechanically is difficult, and the detached fragments of thalli begin immediately to grow again. Liverwort also spreads asexually via diaspores of about $0.5 \mathrm{~mm}$ (Laaka-Lindberg 2016) called gemmae, which develop in bowl-shaped gemmae cups on the surface of thalli (Newby et al. 2007). Gemmae cups begin to form very quickly in the early stages of growth. One gemmae cup consists of 20-25 gemmae (Laaka-Lindberg 2016). Spreading becomes more effective when water splashes onto gemmae cups and causes the gemmae to fly into the air. Gemmae are large compared to sexually produced spores, and are therefore strong and begin to grow rapidly (Laaka-Lindberg 2016). The liverwort is dioecious. Sexual reproduction begins at a later stage of growth. For the purpose of sexual reproduction, the shank produces sperm and egg colonies at the ends of the long supports. About 10000 small spores are formed in one sporadic colony, about 10-15 $\mu \mathrm{m}$ in size, which are ejected (Laaka-Lindberg 2016). 


\section{AGRICULTURAL AND FOOD SCIENCE}

L.E. Särkkä \& R. Tahvonen (2020) 29: 250-256

The most common non-chemical weed control is the use of mulches (Wilen et al. 1999). In experiments, the layer depth of mulch has proved important to achieve the best weed control. Restrictions on the growth of liverwort include e.g. the following mulches: a 1.3-cm layer of hazelnut and oyster shells (Svenson 1998), and a 2.5-cm layer of parboiled rice hull (Altland and Krause 2014). Low irrigation intensity has also improved liverwort control in various mulches (Svenson 1998).

In contrast, poor control of liverwort has been reported with coarse sand, peat, perlite, pumice, and rockwool (Svenson 1998). Other mulch materials for control of weeds are a 2.5-cm layer of recycled paper pellets (Smith et al. 1998), pine bark, and cocoa hull (Abbey and Mervosh 2002, Mervosh and Abbey 1999, Mervosh and Abbey 2002), wheat straw, oat straw, and cereal rye straw (File et al. 2000). An application of mustard seed meal on the thallus of growing liverwort caused necrosis within 2 to 3 days of application and provided up to $97 \%$ control of liverwort (Boydston et al. 2008). A problem with many mulch materials is that they are lightweight, and the wind blows them away from the container surface. Even if these materials are effective, high material and labour costs can prevent their wider use in commercial nurseries (Stewart et al. 2017).

Sawangproh et al. (2016) found a few gnat larvae of the sciarid fly (Scatopsciara cunicularis Lengersdorf) feeding on the living thalli of the liverwort. This has potential for the future biological control of liverwort in greenhouses.

Sphagnum moss has proved a useful growing medium for plants (Gaudig and Joosten 2002, Silvan et al. 2017). Good-quality non-decomposed moss is obtained by collecting only a 30-cm layer of live Sphagnum moss from the top of the mire in Finland. Moss regeneration in mires begins immediately after harvesting, so harvesting is ecologically sustainable (Silvan et al. 2012). In our growing media studies, we have found that weeds do not grow on the surface of the Sphagnum moss. However, no large-scale studies in nurseries have been implemented to obtain the actual effect of Sphagnum mulch layer on the control of liverwort growth on the container surface. In Finland, liverwort in nurseries is especially problematic for plants like rhododendron and blueberry that require an acidic growing medium. The aim of our research was to test Sphagnum moss from different mires, their layer depth, and coarseness on the top of pots for the control of liverwort growth in rhododendron, highbush blueberry, and blackcurrant plants in a commercial nursery. The effect of blackcurrant stem pieces on the growth of liverwort was also tested in a plastic greenhouse.

\section{Material and methods}

Three plant species were used in the experiment: highbush blueberry (Vaccinium corymbosum L.) cv. Northblue, blackcurrant (Ribes nigrum L.) cv. Ola, and rhododendron (Rhododendron) cv. Pohjola's Daughter.

The experiments were prepared at Luke Piikkiö experimental station and cultivated by a commercial nursery in Southwest Finland $\left(60^{\circ} 05^{\prime} 50^{\prime \prime} \mathrm{N}, 023^{\circ} 31^{\prime} 35^{\prime \prime} \mathrm{E}\right)$. The weather conditions in both years are presented in Figure 1.

The highbush blueberry and blackcurrant trials lasted two years; the rhododendron trial lasted one year. The growing medium for blackcurrant was B2 peat, fertilised by dolomite lime $9 \mathrm{~kg} \mathrm{~m}^{-3}$ and N-P-K (9-4-13) fertiliser $1 \mathrm{~kg}$ $\mathrm{m}^{-3}, \mathrm{pH}$ 6.4. The growing medium for blueberry and rhododendron was a mixture of blackcurrant peat and peat without fertilisers and dolomite lime, $\mathrm{pH}$ 4.8. The Sphagnum moss was a mixture of moss species. Most of it was S. fuscum, followed by S. medium, S. balticum and S. rubellum.

In the first spring, one-year-old blueberry and blackcurrant plants were planted in 1-litre pots. In the second year, the same plants were planted in 3-litre pots. The plants were dormant (leafless) at potting. Two-year-old rhododendron plants were planted in 3-litre pots in the first spring. Between week 44 in October/November and week 19 in May, blueberry and blackcurrant plants were stored in cold storage at $\pm 1{ }^{\circ} \mathrm{C}$. No live liverwort was detective on the surface of the pots after cold storage. New growing media and mulches were added in addition to the old substrates.

At potting, free space was left on the surface of the pot for a layer of Sphagnum moss. One- and two-cm Sphagnum moss layers were used for blueberry and blackcurrant. A two-cm layer of Sphagnum moss was used for rhododendron. Sphagnum mosses from different mires were air-dried and sieved. Sphagnum mosses for blueberry and blackcurrant were 10-20 mm, and for rhododendron additionally, 20-40 mm. The Sphagnum mosses were moistened with tap water before application to the pot surface. 


\section{AGRICULTURAL AND FOOD SCIENCE}

Sphagnum moss from three different mires was included in the experiment. In the first year, the Sphagnum mosses originated from mires $\mathrm{M}$ and $\mathrm{B}$, and in the second year from mires $\mathrm{M}$ and $\mathrm{C}$. Sphagnum mosses $\mathrm{M}$ and $\mathrm{C}$ were collected at a depth of 0-30 cm from the surface of the mire. Sphagnum moss B was collected more deeply, because it contained partly decomposed moss (peat). Only the $\mathrm{M}$ moss was used for rhododendron. Mulch materials did not contain nutrients.

After potting at experimental station in Piikkiö, the plants were transported to the nursery for field trials on 14 May 2018 and 16 May 2019. They were placed in the same automatic overhead irrigation area with other plants of the same species in the nursery. Blackcurrat received in July 2019 1.5-2 g pot $^{-1}$ fertiliser N-P-K (11-4.6-17.6 and micronutrients).

The plants were observed twice during the growing season: in July and October 2018; and August and October 2019. Liverwort coverage on the pot surface was observed in percentages.

The experimental design was completely randomised, with six blocks. In each block, there were five blueberry and blackcurrant plants, and three rhododendron plants for each treatment. Liverwort coverage data were analysed with the SAS/MIXED procedure (SAS version 9.4). Comparisons were performed using the HSD test in the SAS/MIXED procedure.

In the summer of 2019, a pilot test with four treatments was performed with blackcurrant cv. Mortti stem pieces in a plastic-covered greenhouse in which liverwort was growing everywhere. The blackcurrant stems were cut in winter from bushes in winter dormancy and stored in a cold room covered with plastic until May. Stems were cut in $1-\mathrm{cm}$ pieces. 0.75 I pots were filled with peat. The control treatment was a peat pot with no plant. In treatment 1 , there were five blackcurrant cuttings in one peat pot. In treatment 2 , the pot surface was covered with a 2-cm layer of blackcurrant stem pieces with no plant. In treatment 3, the pot surface was covered with a 2-cm layer mixture of peat and blackcurrant stem pieces in a ratio of 1:1 with no plant. The liverwort coverage on the pot surface was observed in August and October. The experimental design was completely randomised, with six blocks and two pots in each block. Data were analysed as in the previous experiment.
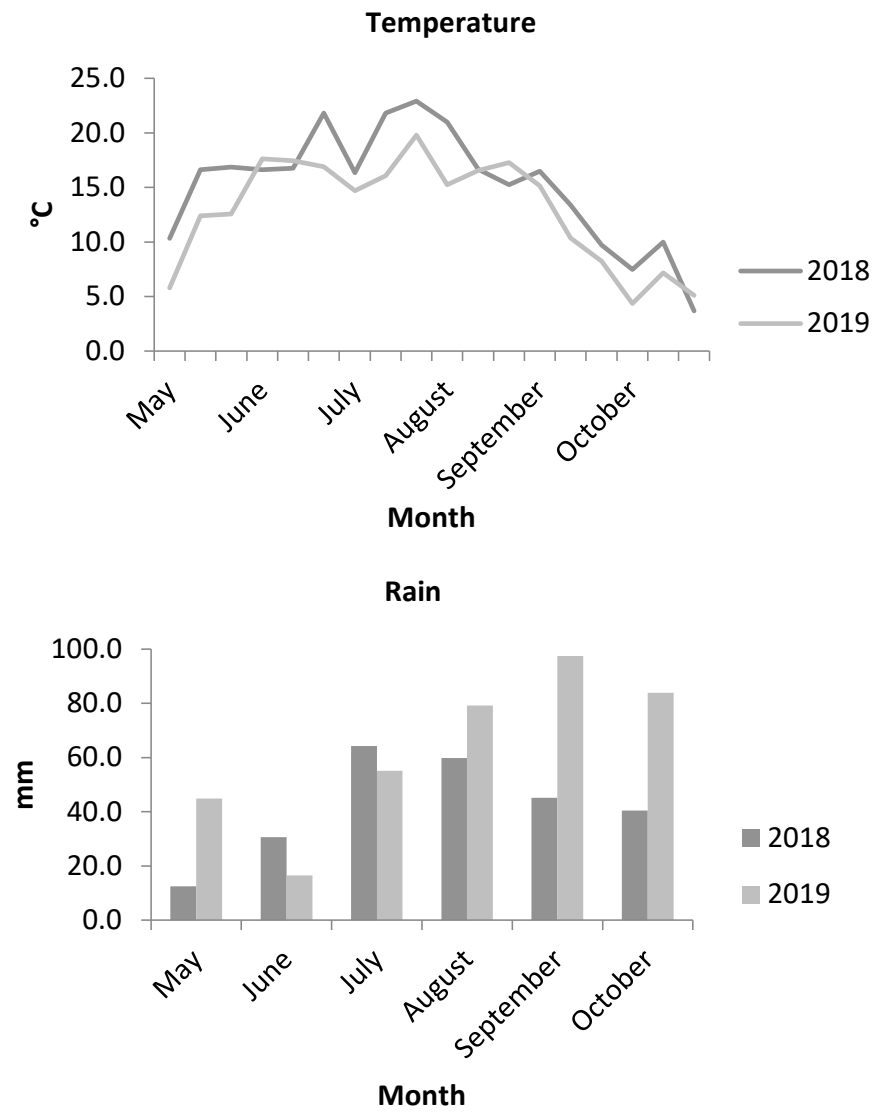

Fig. 1. Mean temperatures $\left({ }^{\circ} \mathrm{C}\right)$ and monthly rainfall $(\mathrm{mm})$ in field conditions in Lohja, Finland (Finnish Meteorological Institute) 


\section{AGRICULTURAL AND FOOD SCIENCE}

\section{Results}

In highbush blueberry, liverwort began to increase more on the pot surface in July 2019 in the control than in the Sphagnum moss mulch (Fig. 2). In August 2018, a quality difference in Sphagnum moss mulch on liverwort invasion efficiency was observed. The coverage of liverwort on the pot surface was higher with Sphagnum moss B (18-30\%), which was more decomposed than in Sphagnum moss M (4.5\%) (Fig. 2). In October, many of the pot surfaces of the control plants were totally covered with liverwort, although the mean coverage values between years varied from 45 to $64 \%$. In October 2019, Sphagnum moss mulches M and C significantly inhibited the growth of liverwort on blueberry pots (10-22\% coverage), compared with partially decomposed Sphagnum moss B (26$35 \%$ coverage) in 2018 and the control (45-64\% coverage) (Fig. 2). The thickness of the Sphagnum moss mulch layer did not differ significantly between treatments.
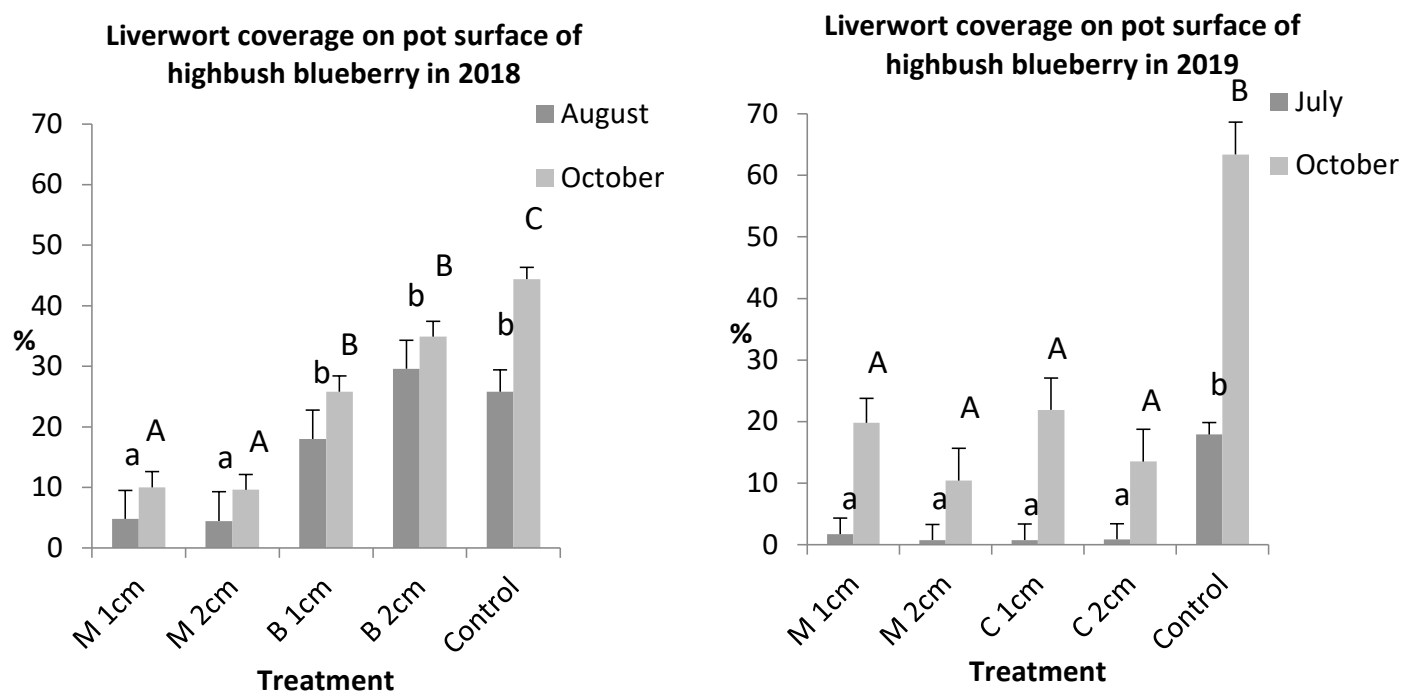

Fig. 2. Mean values and SE of liverwort coverage $\%$ on pot surface of highbush blueberry in different months, years and treatments. M, B and C correspond to different origins of Sphagnum moss, $\mathrm{cm}$ is depth of moss layer on the pot surface at potting. Different letters indicate statistical difference $p \leq 0.05$. Small letters indicate results in July or August, and big letters in October. Treatment $n=30$

Weather conditions appeared to have promoted the growth of liverwort more in 2019 compared to 2018, because rainfall in the autumn of 2019 was much higher than in 2018, and mean temperatures during growing periods were higher in the summer of 2018 than in 2019 (Fig. 1).

In rhododendron, both the Sphagnum moss degrees of coarseness similarly inhibited the growth of liverwort in 2018 (Table 1). In October, liverwort had already started to die on the pot surface.

Table 1. Mean values and SE of liverwort coverage \% on pot surface of rhododendron. Surface was covered with $2 \mathrm{~cm}$ of different coarseness of Sphagnum moss M. Different letters in one column indicate statistical difference $p \leq 0.05$. Treatment $n=18$

\begin{tabular}{lll}
\hline Treatment & Coverage \% & \\
\hline & August & October \\
Sphagnum $10-20 \mathrm{~mm}$ & $2.7 \pm 4.3 \mathrm{a}$ & $5.6 \pm 4.4 \mathrm{a}$ \\
Sphagnum $20-40 \mathrm{~mm}$ & $1.7 \pm 4.2 \mathrm{a}$ & $2.4 \pm 4.3 \mathrm{a}$ \\
Control & $51.8 \pm 4.5 \mathrm{~b}$ & $42.8 \pm 4.6 \mathrm{~b}$ \\
\hline
\end{tabular}

Observations of blackcurrant in 2018 showed that liverwort attacked only a few pot surfaces. Most of the pots were unattached. The dispersion of the results was therefore extensive (Fig. 3). There was no statistical difference between treatments. In July 2019, almost no liverwort was observed on the pots (data not shown). In October 2019 , the liverwort invasion on the pots of Sphagnum treatments was only $0.5 \%$, and in the control, $2.5 \%$. When the blackcurrant plant in the control pot was dead $(n=3)$, the pot surface was covered with liverwort. We anticipated that blackcurrant excreted a growth-inhibiting agent. 


\section{AGRICULTURAL AND FOOD SCIENCE}

Liverwort coverage on pot surface of blackcurrant in 2018

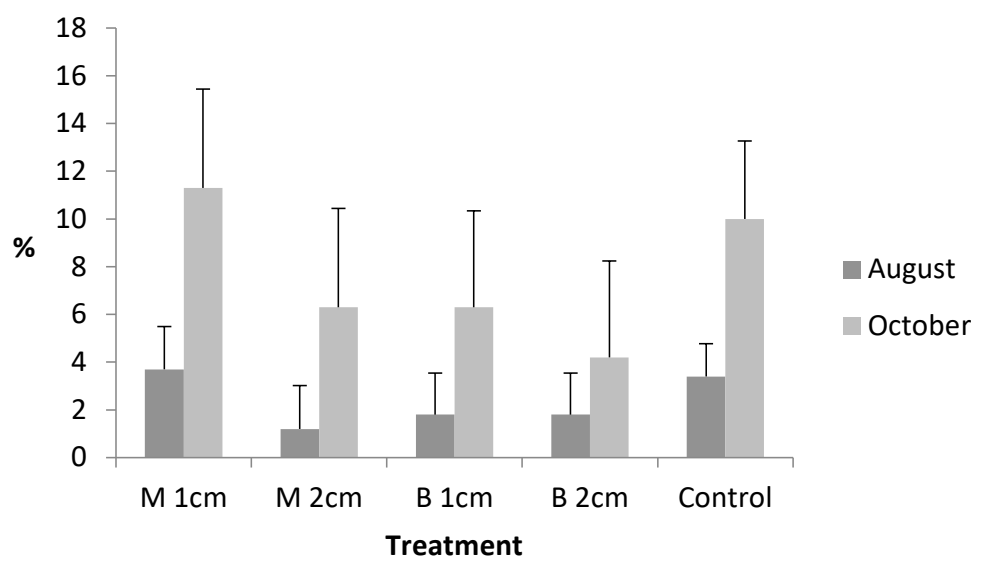

Fig. 3. Mean values and SE of liverwort invation $\%$ on pot surface of blackcurrant plants with different Sphagnum mulches in 2018. Treatment $n=30$

A pilot test in 2019 with blackcurrant stem pieces showed that $26 \%$ of control pot surfaces in August were covered with liverwort. In the other treatments, this ranged between 0 and $9 \%$. In October, liverwort covered the entire surface of the control pots. Hardly any liverwort grew on the pot surface covered with a 2-cm layer of blackcurrant stem pieces with no plant (Fig. 4). When one or more blackcurrant plants were alive in peat pots, or a 2-cm peat/stem pieces mixture covered the surface of pots with no plant, the liverwort invasion was $36-47 \%$. These results support the notion that blackcurrant has a growth-inhibiting character.

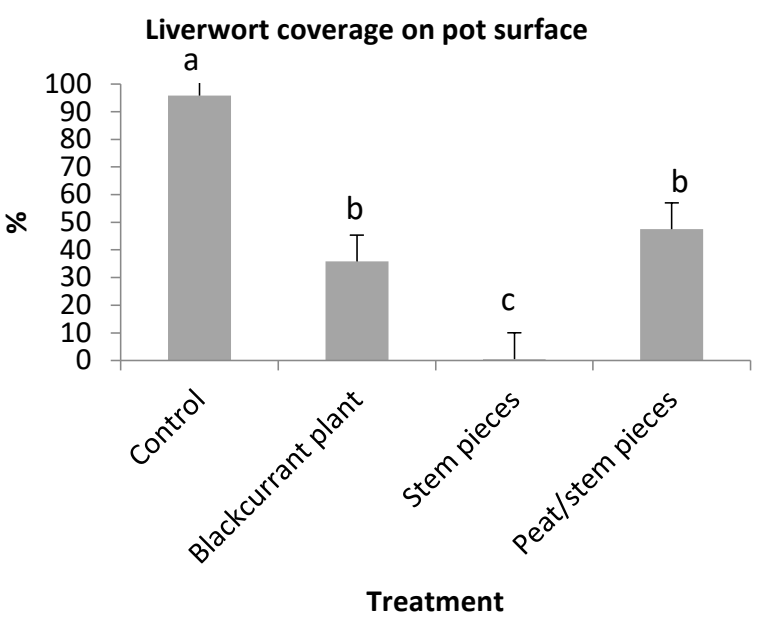

Fig. 4. Liverwort average coverage \% and SE on pot surface of different treatments in October. Different letters indicate statistical difference at $p \leq 0.05$. Treatment $\mathrm{n}=12$

\section{Discussion}

The Sphagnum moss used in our study did not completely control liverwort (Marchantia polymorpha L.) growth. In July-August, the average prevention rate in highbush blueberry was 95-99\%, and in October, it was 78-90\%, depending on the year. In rhododendron and blackcurrant, the control was 90-95\%. Stewart et al. (2017) reported that it was difficult to achieve complete control of weeds on pot surfaces with different kinds of mulch.

Liverwort began to increase on the surface of the pots in July at the latitudes of the experimental location in Finland, while at southern latitudes in America, it increased strongly in May (Wilson and Hughes 1985). Newby et al. (2006) found that in the United States, liverwort had its best growing time at days with a 13-15-hour length and at $18-22^{\circ} \mathrm{C}$, which also seemed to fit the liverwort growth efficiency measured in our experiment. The day length from early summer to mid-August was more than 15 hours and had fallen to less than 13 hours in mid-September. 


\section{AGRICULTURAL AND FOOD SCIENCE}

L.E. Särkkä \& R. Tahvonen (2020) 29: 250-256

The weather conditions in our research had a considerable impact on the growth intensity of liverwort obtained in different years. Temperatures for liverwort growth were more favourable in the rainy summer of 2019 than in 2018. During low rainfall periods, the growth of liverwort can be limited by controlling irrigation intensity. During rainy summers, this is difficult due to the high relative humidity and the uncontrollable amount of water the plants receive. Svenson (1998) has also written that high growing medium humidity increases liverwort growth.

Although the thickness of the Sphagnum moss layer did not significantly affect the suppression rate of liverwort growth in blueberry, the 2-cm mulch layer appeared more effective and at least more secure on the pot surface than the 1-cm layer in the rainy 2019. Irrigation and rainwater drops did not mix with the substrate and flew away from the pot surface as easily with a $2-\mathrm{cm}$ mulch layer as with a $1-\mathrm{cm}$ layer. The mulch layer was important in the liverwort growth suppression efficiency reported by Svenson (1998), and Altland and Krause (2014).

Sphagnum moss resources are substantial in Finland, but the application on the pot surface needs to be easy and non-expensive for large-scale nursery utilisation. The good results of liverwort control meant that the Sphagnum moss being tested as pressed discs could be placed on the surface of the pot during planting. The fact that the effective control of liverwort growth in rhododendron was received at both tested degrees of coarseness offers more potential for the manufacture of pressed discs with a finer coarse quality.

The growth inhibition effect of blackcurrant on liverwort growth was surprising. Much information is available in the literature on the chemical control of liverwort (e.g. Hammet 1976, Fausey 2003, Case et al. 2005), but no use has been reported for substances extracted from blackcurrant. For example, pelargonic acid and acetic acid have been tested as pre-treatments before liverwort growth (Fausey 2003). These chemicals initially had a good effect ( $80 \%$ control), but the efficacy was lost after 11 weeks of application. However, these agents are useful in preventing the spread of liverwort in the nursery. In our study, when blackcurrant plants were growing in both Sphagnum moss mulch and control treatments, the suppression effect against liverwort growth did not differ between treatments. However, in pots that included blackcurrant stem pieces or blackcurrant plants, the control effect against liverwort was obvious compared to the pot without blackcurrant. Extracts of blackcurrant berries and leaves contain antioxidant-active compounds, e.g. phenolic compounds that inhibit the growth of certain microorganisms (Werlein et al. 2005). The stem is comprised of hardwood lignin (Stewart and Brennan 1996). A dry mulch surface has been shown to have a growth inhibition effect on liverwort (Altland et al. 2016), which probably also increased the liverwort growth inhibition effect of blackcurrant stem pieces in our research.

In conclusion, although the use of Sphagnum moss as a mulch cover does not completely prevent the growth of liverwort, it is an ecological option that can significantly reduce the invasion of liverwort on the pot surface throughout the growing season. This positive effect was especially important for acidic growing media. If the use of Sphagnum moss as a growing medium increases, mulch addition on the pot surface may become unnecessary. Furthermore, Sphagnum moss growing media suppress the growth of all kinds of weeds, which would greatly ease their associated problems in nurseries.

\section{Acknowledgements}

We thank the Finnish Horticultural Foundation, Maiju ja Yrjö Rikalan Puutarhasäätiö, for funding this research. We express our gratitude to Tomi Tahvonen, CEO of Puutarha Tahvoset for providing the field of research. We also thank Pirkko Nykänen and Päivi Tuomola for their assistance during the experiments.

\section{References}

Abbey, T.M. \& Mervosh, T.L. 2002. Mulches for weed suppression in containers of herbaceous perennials. Proceedings of the Northeastern Weed Science Society 56: 76.

Altland, J.E., Boldt, J.K. \& Krause, C.C. 2016. Rice Hull Mulch Affects Germination of Bittercress and Creeping Woodsorrel in Container Plant Culture. American Journal of Plant Sciences 7: 2359-2375. https://doi.org/10.4236/ajps.2016.716207

Altland, J. \& Krause, C. 2014. Parboiled Rice Hull Mulch in Containers Reduces Liverwort and Flexuous Bittercress Growth. Journal of Environmental Horticulture 32: 59-63.

Boydston, R.A., Anderson, T. \& Vaughn, S.F. 2008. Mustard (Sinapis alba) seed meal suppresses weeds in container grown ornamentals. HortScience 43: 800-803. https://doi.org/10.21273/HORTSCI.43.3.800

Case, L.T., Mathers, H.M. \& Senesac, A.F. 2005. A Review of Weed Control Practices in Container Nurseries. HortTechnology 15: 535-545. https://doi.org/10.21273/HORTTECH.15.3.0535 


\section{AGRICULTURAL AND FOOD SCIENCE}

Fausey, J.C. 2003. Controlling Liverwort and Moss Now and in the Future. HortTechnology 13: 35-38. https://doi.org/10.21273/HORTTECH.13.1.0035

File, S.L., Knight, P., Gilliam, C., Reynolds, D. \& Altland, J. 2000. Evaluation of alternative weed control options for ornamentals grown in large containers. Proceedings of the Southern Nursery Association Research Conference 45: $397-402$.

Gaudig, G. \& Joosten, H. 2002. Peat moss (Sphagnum) as a renewable resource - an alternative to Sphagnum peat in horticulture? Proceedings of the 2002 International Peat Society Symposium. Pärnu, Estonia. p. 117-125.

Hammett, K.R.W. 1976. Control of liverwort growth on the surface of soil in plant containers. New Zealand Journal of Experimental Agriculture 4: 117-119. https://doi.org/10.1080/03015521.1976.10425855

Laaka-Lindberg, S. 2016. Keuhkosammal Marchantia polymorpha - taimitarhojen haasteellinen rikka. Taimiuutiset 14: 9-11. ISSN 2242-9395.

Mervosh, T.L. \& Abbey, T.M. 1999. Evaluation of fabric discs, mulches, and herbicides for preventing weeds in containers. Proceedings of the Northeastern Weed Science Society 53: 122.

Mervosh, T.L. \& Abbey, T.M. 2002. Weed management alternatives for container-grown shrubs. Proceedings of the Northeastern Weed Science Society 56: 75.

Newby, A., Altland, J.E., Gilliam, C.H. \& Wehtje, G. 2006. Postemergence Liverwort Control in Container-Grown nursery Crops. Journal of Environmental Horticulture 24: 230-236.

Newby, A., Altland, J.E., Gilliam, C.H. \& Wehtje, G. 2007. Pre-emergence Liverwort Control in Nursery Containers. HortTechnology 17: 496-500. https://doi.org/10.21273/HORTTECH.17.4.496

Poteri, M. 2002. Maksasammalet kiusaavat taimikasvatusta. Taimiuutiset 5: 17-18. http://urn.fi/URN:NBN:fi-metla-201211066685

Sawangproh, W., Ekroos, J. \& Cronberg, N. 2016. The effect of ambient temperature on larvae of Scatopsciara cinicularius (Diptera: Sciaridae) feeding on the thallose liverwort Marchantia polymorpha. European Journal of Entomology 113: 259-264. https://doi.org/10.14411/eje.2016.030

Shimamura, M. 2016. Marchantia polymorpha: Taxonomy, Phylogeny and Morphology of a Model System. Plant Cell Physiology 57: 230-256. https://doi.org/10.1093/pcp/pcv192

Silvan, N., Silvan, K., Näkkilä, J., Tahvonen, R. \& Reinikainen, O. 2012. Renewability, use and properties of Sphagnum biomass for growing media purposes. In: Proceedings of the 14th International peat Congress. Stockholm, Sweden. Extended abstract number 55: $5 \mathrm{p}$.

Silvan, N., Jokinen, K., Näkkilä, J. \& Tahvonen, R. 2017. Swift recovery of Sphagnum carpet and carbon sequestration after shallow Sphagnum biomass harvesting. Mires and Peat 20: 1-11. http://www.mires-and-peat.net/

Smith, D.R., Gilliam, C.H., Edwards, J.H., Olive, J.W., Eakes, D.J \& Williams, J.D. 1998. Recycled Waste Paper as a Nonchemical Alternative for Weed Control in Container Production. Journal of Environmental Horticulture 16: 69-75.

Stewart, C.J., Marble, S.C. \& Pearson, B.J. 2017. Impact of Container Nursery Production Practices on Weed Growth and Herbicide Performance. HortScience 52: 1593-1600. https://doi.org/10.21273/HORTSCI12241-17

Stewart, D. \& Brennan, R.M. 1996. 3-Blackcurrant stems - An agri-waste with potential as a diluent to existing tree-based fibre sources. The Chemistry and Processing of Wood and Plant Fibrous Material. Cellucon '94 Proceedins. p. 25-30. https://doi.org/10.1533/9781845698690.25

Svenson, S.E. 1998. Suppression of Liverwort Growth in Containers Using Irrigation, Mulches, Fertilizers, and Herbicides. HortScience 33: 484 (abstract 231). https://doi.org/10.21273/HORTSCI.33.3.485a

Voth, P.D. \& Hamner, K.C. 1941. Responses of Marchantia polymorpha to Nutrient Supply and Photoperiod. Botanical Gazette 102: 169-205. https://doi.org/10.1086/334943

Werlein, H.-D., Kütemeyer, C., Schatton, G., Hubbermann, E.M. \& Schwarz, K. 2005. Influence of elderberry and blackcurrant concentrates on the growth of microorganisms. Food Control 16: 729-733. https://doi.org/10.1016/j.foodcont.2004.06.011

Wilen, C.H., Schuch, U.K. \& Elmore, C.L. 1999. Mulches and subirrigation control weeds in container production. Journal of Environmental Horticulture 17: 174-180. https://doi.org/10.1080/01448765.1999.9754839

Wilson, D. \& Hughes, A. 1985. Evaluation of oryzalin and Mogeton for weed control in field and container grown hardy nursery stock. Proceedings of the British Crop Protection Conference, Weeds 3: 1095-1102. 